\title{
REFLEXIONES EN TORNO AL CLÍTICO SE EN ESPAÑOL
}

\author{
Susana AzPiazu Torres \\ Universidad de Salamanca \\ sazpiazu@usal.es
}

\section{Resumen}

This paper proposes a new approach to the formal and semantic problems of the description of se in Spanish. These problems are concerned with the morphological status of se, its syntactical behavior and, above all, the complexity of its semantic implications, which are mostly hardly structured in the language, such as reflexivity, diathesis, impersonality, etc. The semantic functions of se cover a broad spectrum of syntactic and conceptual nuances, which take the form of a continuum starting with a subject-responsible predicate and ending with a predicate with no subject at all. I will also distinguish here two different se-types in Spanish: the so-named "diathetic" one, which is the formal representative of the medium voice in Spanish, and the expletive one, whis is related to the expression of verbal aspect and is therefore more attached to the predicate's interpretation.

\section{Introducción. Valores de se en español}

1.1. El problema de los verbos pronominales y la polémica cuestión de la existencia de una voz media en español es un tema clásico de las descripciones del español. Pese a que las distintas aproximaciones al tema se afanan por lograr una clasificación de las distintas apariciones del se que resulte más o menos homogénea y coherente, lo que impera en los resultados es la heterogeneidad. Para abordar este tema, los gramáticos se ven obligados a emplear toda la batería de sus criterios metodológicos. No es raro, por ejemplo, que para distinguir tipos de se se recurra a su estatus morfológico (pronombre frente a morfema), y que más adelante se establezcan subclasificaciones en las que intervienen los más variados parámetros semánticos, tanto el valor que aporta el pronombre (reflexividad ${ }^{1}$, medialidad $^{2}$, valor incoativo ${ }^{3}$, aspectual ${ }^{4}$, metonímico $^{5}$, pasivo $^{6}$ ), como el tipo de verbo al que acompaña

Trujillo (1992).

2 El hecho de que el español carezca de un paradigma formal propio para la expresión de medialidad es sin duda una de las razones de que haya tan poca unanimidad entre los autores a la hora de considerar la voz media en español. Ver, por ejemplo, las diferencias en la concepción de esta categoría en Alcina/Blecua (1975), Martín Zorraquino (1979), Iglesias Bango (1991) o Mendikoetxea (1999), sin olvidar las observaciones más desarrolladas de Cartagena (1972), autor que, sin embargo, no considera necesario recurrir a este concepto para explicar el funcionamiento de las construcciones pronominales.

3 Luján (1976), Mendikoetxea (1999).

4 Zagona (1996), De Miguel / Fernández Lagunilla (2000).

5 Melis (1996).

6 Mendikoetxea (1999). Para una visión completa de las facetas del se remito al reciente trabajo de Sánchez López (2002). 
(transitivo, intransitivo, anímico, de movimiento), sin olvidar las consecuencias sintácticas de la pronominalización (intransitivación, impersonalización, etc.). A primera vista es sobre todo la interpretación semántica la que más problemas metodológicos plantea, pues es frecuente que los mismos tipos de construcciones se clasifiquen bajo perspectivas y etiquetas diferentes. Donde unos autores ven procesos aspectuales que afectan al verbo, ven otros procesos anímicos que afectan al sujeto, lo que sin duda no tiene por qué ser incompatible. $\mathrm{Ni}$ siquiera hay coincidencia a la hora de interpretar en general el fenómeno: muchos autores hablan de reflexividad en un sentido muy amplio, incluyendo bajo esta rúbrica manifestaciones sintácticas y semánticas muy dispares. Otros, más cautos, prefieren comprometerse menos y hablar simplemente de "construcciones pronominales".

Por otra parte, tampoco las interpretaciones sintácticas son coincidentes, ni en los aspectos aparentemente más evidentes: algunos autores admiten que se desempeña a veces funciones argumentales propias del nombre y otras funciones verbales $\mathrm{u}$ oracionales ${ }^{7}$, pero la inclusión de unas y otras en clases bien delimitadas dista mucho de ser unívoca ${ }^{8}$. Los mismos autores suelen ser conscientes de estas limitaciones. Así, Mendikoetxea (1999), en su estudio sobre las construcciones impersonales con se, pone de relieve "la inestabilidad de los esquemas sintácticos relacionados con estas oraciones" y, al mencionar los contextos no transitivos afirma que "existen restricciones de difícil explicación que afectan a estas oraciones, sobre las que es muy difícil obtener juicios válidos de los hablantes". La consecuencia de todo ello es que hay casi tantas clasificaciones distintas como intentos se han hecho por clasificar.

1.2. Como en tantas ocasiones a la hora de analizar un fenómeno lingüístico, hay que partir del hecho de que los diferentes acercamientos al tema no son falsos o erróneos en sí mismos, sino simplemente diferentes maneras de abordarlo. En el caso que nos ocupa esto es tanto más cierto, cuanto que la gramática parece no estar en condiciones de resolver estas cuestiones con sus herramientas "ortodoxas", aquellas que está acostumbrada a manejar y que además son las únicas que está capacitada para manejar. Nuestra hipótesis es que nos hallamos ante un fenómeno lingüístico "poco estructural", de modo que al abordarlo científicamente los métodos de análisis, estructurales por definición, topan con serias limitaciones. La mayor de ellas es que, como afirma Mendikoetxea, hay casos flagrantes de inestabilidad en el uso por parte de los hablantes. Un caso de vacilación lo tenemos, por ejemplo, en la actualización de la concordancia en las construcciones pasivas con se. Las citas que siguen aparecen en Mendikoetxea (1999: 1679):

$7 \quad$ El problema se plantea sobre todo cuando se trata de delimitar las funciones verbales que no responden al esquema ni del OD ni del OI (pues se no puede ser sustituido por el resto de los clíticos de tercera persona no reflexivos lo, la, los, las - le, les); es decir, en casos como se arrepiente, se alegra de que vengas, se abre el telón. En estos casos lo normal es trasladar el problema de la sintaxis a la semántica de casos y hablar de roles "agente", "experimentante", "paciente", etc.

8 Ni siquiera todos los autores están de acuerdo en esta partición; ver Trujillo (1992), que postula un valor único de "sujeto interno" para todos los casos de se. Más arriesgada es la propuesta generativista que pretende que se puede asimilarse a los adverbiales aspectuales; ver Zagona (1996) y De Miguel / Fernández Lagunilla (2000).

$9 \quad$ Mendikoetxea (1999: 1704). 
(1) Caruana lamenta que no se hayan entregado a los cuarteles más banderas

(2) Caruana se lamentó de que "en Zaragoza no se haya entregado a los cuarteles más banderas constitucionales"

Otro tipo de vacilación es el que se relaciona con el uso de las secuencias pronominales para referentes de cosa cuando la estructura no es impersonal:

(3) $[\ldots]$ y en cuanto al dinero [...] si se lo maneja con prudencia ${ }^{10}$

donde lo remite a lo que originariamente sería el sujeto de la oración: el dinero se maneja con prudencia. Es posible que en estos casos el hablante esté interpretando se como marca pronominal del sujeto y el sintagma nominal como OD, pero ello no deja de plantear serios problemas de descripción a la gramática, que se ve obligada a aceptar como "gramaticales" proyecciones claramente anómalas como (3).

El contraste entre las llamadas "pasivas reflejas" y las oraciones impersonales es también un buen exponente del desfase entre uso y descripción:

(4) En la sesión de ayer se criticaron los presupuestos

En la sesión de ayer se criticó al ministro de Hacienda

Desde el punto de vista nocional parece absurdo tratar de establecer diferencias entre (4) y (5) y, sin embargo, estamos ante dos formaciones sintácticas diferentes, una personal y otra impersonal.

Las vacilaciones del hablante afectan también a estructuras no siempre tan problemáticas desde el punto de vista sintáctico. La rección pronominal de muchos verbos está sujeta a variables más específicas que se relacionan con las variedades del diasistema. Así, muchos modismos de la lengua coloquial se constituyen a partir del uso metafórico de algunos verbos que adoptan el pronombre ${ }^{11}$ : apañárselas, buscarse la vida, saltarse un semáforo, etc.; el llamado "se expletivo" es propio de la lengua familiar oral más que de la escrita (¿te lo vas a comer todo?), y la supuesta alternancia de expresiones con o sin pronombre responde básicamente a usos dialectales: engordar - engordarse ${ }^{12}$; regresar-regresarse; andar-andarse e incluso vivir-vivirse ${ }^{13}$. Por eso mismo no se puede pretender que las construcciones pronominales del español coincidan con los usos de este mismo clítico en otras lenguas románicas. Como trataremos de mostrar aquí, el empleo de se es uno de los fenómenos de

10 Citado por M. Zorraquino (1979: 173). La cita pertenece a F. Ayala, Muertes de perro, Madrid, Alianza, 1972, pág. 220.

11 Ver Hummel (2000: 256, nota 7).

12 Para De Miguel / Fernández Lagunilla (2000) este tipo de estructura sería incorrecta, pues el verbo engordar designa un evento de acabamiento gradual, que no acepta la aparición del operador aspectual se. Sin embargo, su estudio no tiene en cuenta variedades diatópicas y adolece en parte del defecto que mencionábamos antes: el de intentar que los datos se adecuen al modelo, en vez de lo contrario.

13 No todos los usos dialectales están igual de bien atestiguados. Martín Zorraquino (1979: 277-338) presenta gran cantidad de ejemplos pertenecientes a distintas zonas de habla hispánica. Pero lo cierto es que los hablantes sorprenden continuamente con nuevas construcciones que no siempre se recogen en los estudios. Yo he podido oír repetidamente en hablantes riojanos expresiones como Ángel se vive en la calle Mayor, que no aparece recogida en ningún estudio sobre el tema. Falta seguramente un estudio variacionista más exhaustivo del uso de este clítico en las hablas españolas. 
la lengua en el que intervienen más elementos semánticos y expresivos diferentes, entre otras cosas porque aquí se pone de manifiesto la percepción que el hablante tiene del modo en que se desarrollan los eventos ${ }^{14}$.

1.3. Una vez detectados algunos de los problemas descriptivos que presentan estas construcciones, parece que la forma más sensata de dar cuenta de ellas es dejando a un lado la casuística para intentar aportar una descripción más general que aspire no a la coherencia de los casos particulares, sino al principio global que los gobierna. Se trata, pues, de abordar el estudio del clítico con la convicción de que hay algo común a todas sus manifestaciones concretas, algo que tal vez no sea fácil de describir estructuralmente, pero que rige y explica sus manifestaciones, desde las más léxicas a las más gramaticalizadas. Evidentemente, estamos postulando un enfoque semántico-conceptual del problema, lo que nos obliga a pasar por alto cuestiones importantes relacionadas con el funcionamiento sintáctico de estas unidades. De hecho, este es el camino que terminan por adoptar también la mayoría de los estudiosos del tema.

En Trujillo (1992) encontramos algunas ideas que apuntan en la misma línea de explicación básica y homogeneizadora a la que se aspira aqui. Para este autor, todas estas construcciones sintácticas son formas "reflexivas" que representan variantes contextuales de una sola forma sintáctica. Esta forma sintáctica se caracteriza semánticamente por expresar un proceso que se origina en el predicado y presenta, por tanto, un sujeto interno a él. Este sujeto interno no es correferente con ningún sujeto externo, sino que lo atrae cuando lo hay contextualmente ${ }^{15}$. Así, para Trujillo, todas las diferencias de interpretación entre las construcciones reflexivas se explican por la diferente semántica del predicado (Juan se lava y Juan se rie) o del sujeto (El juez se vende y La novela se vende) o incluso por diferencias situacionales (María se animó (a sí misma / con tus palabras), pero en ningún caso responden a estructuras sintácticas diferentes. También para Coseriu (1981: 212) los distintos valores de algunas de estas construcciones responden a determinaciones contextuales, es decir, al modo en que el hablante interpreta el enunciado según su conocimiento del mundo.

La noción de "reflexividad" que postula Trujillo equipara semántica y estructuralmente Pedro se lava con Aqui se come bien, lo cual tal vez no sea equivocado pero resulta poco preciso. Entre ambas oraciones hay diferencias semánticas importantes que seguramente podrían explicarse desde la misma concepción de la reflexividad de Trujillo, y que forman parte también de su definición. Por otra parte, la idea de la reflexividad es, en última instancia, también una noción diatética, esto es, se refiere al grado de implicación del sujeto en el evento. Desde esta perspectiva, el comportamiento semántico de se pone de manifiesto una serie de valores que obligan a replantear el problema de la voz en español y que ofrece un espectro amplio de matices sintácticos y conceptuales. Este espectro se presenta como un continuo que comienza con un sujeto pleno que centraliza la atención del predicado y termina diluyéndose a favor de las propiedades eventivas del predicado. Distinguimos así dos tipos de se en español: el tipo que llamamos "diatético" y que en definitiva es el representan-

14 La perspectiva cognitivista del fenómeno de la medialidad es una manera de abordar su carácter idiosincrático. Es, por ejemplo, el enfoque que adopta Manney (1998) en su estudio sobre la voz media en griego moderno. Así, los usos peculiares de la diáteisis se justificarían por el hecho de que "linguistic meaning is partly determined by speaker perspective" (Manney, 1998: 57).

15 Trujillo (1992: 148). 
te formal de los valores de la diátesis media en español, y el tipo expletivo, relacionado con la expresión del aspecto, que afecta más propiamente a la interpretación del predicado ${ }^{16}$.

\section{Se diatético}

2.1. Trujillo afirma que las construcciones reflexivas se caracterizan por su valor referencial activo y pasivo a la vez. En este contraste entre los dos valores ve el autor el carácter "medio" de estas construcciones ${ }^{17}$, carácter que define como la diátesis marcada. Sin entrar en polémicas sobre si es pertinente o no considerar que en español existe la "voz media" ni sobre si se parece en algo o no a la voz media del griego o de las lenguas indoiranias, lo que evidencian las estructuras con se es una manera diferente de enfocar el papel del sujeto y el del predicado en la oración. En realidad, y en contra de lo que postula Trujillo, el carácter medial de se no consiste en anular el contraste activa-pasiva, sino en despojar al predicado de los rasgos propios de la activa y de la pasiva. En este punto hay que señalar que, tal como muestran el griego y las lenguas indoiranias clásicas ${ }^{18}$, la verdadera oposición diatética que se da en indoeuropeo no es activa / pasiva sino activa / media, siendo la pasiva una modalidad derivada de la media ${ }^{19}$. En efecto, según Benveniste los eventos se contemplan desde una de estas dos perspectivas:

Dans l'actif, les verbes dénotent un procès que s'accomplit à partir du sujet et hors de lui. Dans le moyen, qui est la diathèse à définir par opposition, le verbe indique un procès dont le sujet est le siège; le sujet est intérieur au procès ${ }^{20}$.

La consecuencia de esta interiorización del sujeto en el proceso puede definirse también como pérdida de control del agente en el evento designado por el verbo, de modo que se produce un paso gradual del esquema "sujeto hace" a un esquema "sujeto experimenta" $\rightarrow$ "sujeto padece"21. De este modo, el sujeto deja de ser realmente activo, es decir, de influir sobre el exterior, para centrarse en sí mismo. La lengua ofrece diversas modalidades de este proceso, tal como ilustramos a continuación, y en sus resultados se entremezclan efectos sintácticos con semánticos no siempre de forma simétrica, lo que dificulta la descripción: por una parte, hay un proceso claro de intransitivación de estructuras, vinculado a otro de

16 Como puede apreciarse, en este estudio no nos ocuparemos del llamado dativo (benefactivo para algunos autores), pues entendemos que no forma parte del mismo proceso de medialidad. Se relaciona con el se aspectual en su carácter expletivo, sino embargo, nunca remite al sujeto (como se aprecia en el hecho de que en realidad no es una forma reflexiva: Su hijo no le estudia nada).

17 Trujillo (1992: 158).

18 Ver Humbert (1945), Benveniste (1966) o Kellens (1984).

19 Como se sabe, la pasiva "propiamente dicha", la participial, es de poco uso en español. Además de razones de orden sintáctico y semántico (por ejemplo, las restricciones que presenta el predicado), ello podría ser la consecuencia del hecho, corroborado también por Monge (1955), de que la oposición diatética básica no es activa-pasiva sino activa-media.

20 Benveniste (1966: 172). Vemos aquí la referencia al "sujeto interno" de que habla también Trujillo (1992) a propósito de la reflexividad.

21 Es interesante destacar la conclusión a la que llega Gotō (1987: 55) tras su análisis de la voz media en védico. Según este autor, el rasgo semántico que más se generaliza en los predicados medios es el intransitivo-fientivo, es decir, la expresión de un proceso que se lleva a cabo en el sujeto sin que haya una intención o un afán especial por su parte. 
pérdida de animicidad (sujeto animado $\rightarrow$ sujeto inanimado) y de pérdida de agentización (sujeto agente voluntario $\rightarrow$ sujeto experimentante no voluntario $\rightarrow$ sujeto paciente). En el esquema que sigue intentamos mostrar que estamos ante un proceso cuya culminación se da en una estructura semántica que retoma de nuevo la agentización, sólo que focalizando esta vez la atención en el paciente: la estructura pasiva. Es importante destacar que este proceso se corresponde perfectamente con la extensión histórica del uso del pronombre reflexivo desde el latín a las lenguas románicas. Así, si los valores más o menos mediales suponen una evolución del reflexivo latino que ya se encuentran esbozados en bajo latín y protorromance, los últimos valores, el pasivo y el impersonal, son innovaciones propias de las lenguas románicas ${ }^{22}$.

\begin{tabular}{|c|c|c|c|c|c|c|c|}
\hline \multicolumn{5}{|c|}{ SUJETO ANIMADO } & \multicolumn{2}{|c|}{ SUJETO INANIMADO } & No SUJETo \\
\hline $\begin{array}{l}\text { 1. Refle- } \\
\text { xivo }^{23}\end{array}$ & $\begin{array}{l}\text { 2. Causa- } \\
\text { tivo }\end{array}$ & $\begin{array}{l}\text { 3. Agentivo } \\
\text { intransitivo }\end{array}$ & $\begin{array}{l}\text { 4. Media } \\
\text { anímica }\end{array}$ & $\begin{array}{l}\text { 5. Media } \\
\text { dinámica }\end{array}$ & $\begin{array}{l}\text { 6. Media } \\
\text { incoativa }\end{array}$ & $\begin{array}{l}\text { 7. Agentiva } \\
\text { indefinida } \rightarrow \\
\text { Media pasiva }\end{array}$ & 8. Impersonal \\
\hline $\begin{array}{l}\text { El fraile se } \\
\text { inculpó en } \\
\text { el juicio }\end{array}$ & $\begin{array}{l}\text { Voy a cor- } \\
\text { tarme el } \\
\text { pelo }\end{array}$ & $\begin{array}{l}\text { El fraile se } \\
\text { retractó - Se } \\
\text { refiere a ti - } \\
\text { Siéntate }\end{array}$ & $\begin{array}{l}\text { Me alegro } \\
\text { de que ven- } \\
\text { gas - Me } \\
\text { estoy ma- } \\
\text { reando }\end{array}$ & $\begin{array}{l}\text { Nos salimos } \\
\text { de la ca- } \\
\text { rretera }-\mathrm{Se} \\
\text { murió de } \\
\text { cáncer }\end{array}$ & $\begin{array}{l}\text { Se ha roto } \\
\text { la taza - } \\
\text { Este tejido } \\
\text { se estropea } \\
\text { enseguida }\end{array}$ & $\begin{array}{l}\text { Se quemó el } \\
\text { bosque para } \\
\text { acabar con } \\
\text { la plaga }\end{array}$ & $\begin{array}{l}\text { No se sabe } \\
\text { nada nuevo } \\
\text { - Se detuvo } \\
\text { a los ladro- } \\
\text { nes }\end{array}$ \\
\hline
\end{tabular}

\begin{tabular}{|l|c|c|c|c|c|c|c|}
\hline $\begin{array}{c}\mathrm{S}^{24}= \\
\text { Agente }= \\
\text { Paciente }\end{array}$ & $\begin{array}{c}\mathrm{S}= \\
\text { Paciente } \\
\text { Agente } \\
(?)\end{array}$ & $\begin{array}{c}\mathrm{S}=\text { Agente } \\
\text { (no pacien- } \\
\text { te) }\end{array}$ & $\begin{array}{c}\mathrm{S}=\mathrm{Ex}- \\
\text { periment. } \\
\text { animado }\end{array}$ & $\begin{array}{c}\mathrm{S}=\text { Agente } \\
\text { /Experimen. } \\
\text { animado }\end{array}$ & $\begin{array}{c}\mathrm{S}=\text { Experi- } \\
\text { men. inani- } \\
\text { mado }\end{array}$ & $\begin{array}{c}\mathrm{S}=\text { Paciente } \\
\text { Agente } \\
\text { animado y } \\
\text { desconocido }\end{array}$ & $\begin{array}{c}\mathrm{S}=\emptyset \\
\text { Agente } \\
\text { animado y } \\
\text { descono- } \\
\text { cido }\end{array}$ \\
\hline $\begin{array}{l}\text { estr. transitiva } \\
\text { + TRANSITIVIDAD }\end{array}$ & $\begin{array}{l}\text { estructura intransitiva } \\
\text { - TRANSITIVIDAD }\end{array}$ & $\begin{array}{l}\text { estr. trans. / } \\
\text { intrans. }\end{array}$ \\
\hline
\end{tabular}

2.2. La primera partición establece tres grandes grupos en función de la subcategorización semántica del sujeto: de 1. a 5. el sujeto es animado; en 6. y 7., inanimado, y en 7. no hay sujeto gramatical. Esto tiene repercusiones evidentes sobre el paradigma formal del clítico, pues en los cinco primeros tipos podemos encontrar todas las formas personales del paradigma (me, te, se, nos, os), mientras que en los tres últimos la única forma posible es se.

El camino se inicia con los verbos transitivos en los que los roles de agente y paciente confluyen en el sujeto, que controla totalmente las consecuencias de su acción: El fraile se inculpó en el juicio. Este tipo de construcciones son las que más se acercan a las estructuras activas no pronominales, del tipo El testigo inculpó al fraile en el juicio. El segundo tipo (Voy a cortarme el pelo) es el causativo, en el que el sujeto no es agente, sino paciente,

23 Bajo esta etiqueta se incluyen tanto las tradicionales estructuras reflexivas, como las recíprocas, que entendemos como una variante sintáctica de aquellas. 
aunque él provoca a la realización del evento ${ }^{25}$. Entre este tipo y el siguiente (El fraile se retract $\left.{ }^{26}\right)$ no puede hablarse de pérdida de agenticidad, sino más bien lo contrario; sin embargo, sí hay una reducción de transitividad. Por este motivo el grupo 3, recibe el nombre de "agentivo intransitivo". En este grupo hay tanto verbos puramente pronominales (y, por lo tanto, intransitivos), como verbos que en su forma no pronominal son transitivos. En todos ellos hay, por tanto, un agente, pero se ha bloqueado la posibilidad de un argumento externo, lo que es sin duda un claro indicio de medialidad, pues es el agente el que asume las repercusiones del evento ${ }^{27}$. El tipo 4. (Me alegro de que vengas) representa una pérdida mayor de control sobre la acción: a pesar de que el sujeto es animado, es un experimentante del evento que protagoniza ${ }^{28}$, que suele ser un proceso anímico y no una acción: acordarse, alegrarse, enfadarse, quejarse, etc. ${ }^{29}$. El rol del experimentante es, por tanto, un punto de culminación en el proceso diatético que lleva al sujeto de ser el controlador de su acción a perder el control sobre ella.

2.3. El paso siguiente merece una explicación algo más detallada. Estamos ante el fenómeno de la pronominalización de verbos intransitivos (caer - caerse; dormir - dormirse; ir - irse; etc.). Este tipo de construcción se da sistemáticamente en las lenguas con voz media morfológica $a^{30}$ y tiene un fuerte valor expresivo. Sin embargo, la inclusión de este tipo de verbos dentro del continuo diatético de se no suele ser común en las descripciones de español, tal vez por ser el único tipo que no se ve afectado directamente por el fenómeno de la pérdida de transitividad. De hecho, De Miguel / F. Lagunilla (2000) y Sánchez López (2002) incluyen estos verbos dentro de su estudio del se aspectual. La hipótesis se justifica desde el análisis de la estructura interna de los eventos y trata de explicar la aparición de se junto a verbos intransitivos que implican una transición entre dos puntos de culminación (dormirse, irse, caerse...), pero no los que denotan logros simples, que ocurren en un punto (nacer, llegar), los que denotan la culminación en un punto, detrás del cual viene un proceso (hervir, florecer) o los que tienen un acabamiento gradual (adelgazar, encanecer). Sin embargo, muchos de los verbos que estas autoras aducen para justificar su teoría presentan serios problemas. Por ejemplo, verbos como engordar, regresar o llegar, que se excluyen en el trabajo como portadores de se, pueden atestiguarse con pronombres en ciertas variedades dialectales y sociales ${ }^{31}$. Pero quizá el mejor exponente de los problemas de este enfoque lo representa el doblete salir - salirse. Este verbo denota claramente que la idea de cambio

25 Como señalan respectivamente Humbert (1945: 106) y Gotō (1987: 27-28 nota 8, 52 sigs.) el valor causativo es uno de los efectos propios de la voz media en griego antiguo y védico.

26 Como se aprecia, no estamos tratando aparte los verbos puramente pronominales, aquellos que no tienen una contrapartida no pronominal, pues lo que se juzga aquí no es la formación de la estructura sintáctica sino el efecto semántico del clítico sobre el verbo. Lo mismo puede decirse de algunos casos del grupo siguiente (4.).

27 Ver Manney (1998: 31-32). Vera Luján (1996-97) y Bogard (1999) llaman a este tipo construcciones ergativas o "antipasivas".

28 Este grupo y el siguiente representan lo que autores como Kellens o Gotō denominan "media reflexiva indirecta".

29 Ver nota 24 sobre los verbos puramente pronominales.

30 Humbert (1945) y Kellens (1984) lo denominan "media dinámica". La construcción española procede, evidentemente, de la construcción pronominal equivalente en latín (Bassols de Climent 1983: 282).

31 Las autoras mencionan esta posibilidad en la nota 8 de su trabajo, pero no abordan la cuestión, que, evidentemente, supone un serio obstáculo a su hipótesis descriptiva. 
de estado tras un proceso es secundaria en este tipo de verbos intransitivos. En efecto, la diferencia entre salirse o caerse y la forma no pronominal del verbo correspondiente no estriba en que estos designan un cambio de estado del sujeto (salir y caer también designan cambios de estado tras un proceso), sino que el proceso que designan se vincula a una causa, animada o inanimada, que es relevante para su realización pero que, sin embargo, queda silenciada. En estas construcciones el sujeto puede ser experimentante o agente, pero en este último caso no siempre controla totalmente sus acciones, pues la causa de su acción puede ser ajena a él.

De este modo se explicaría que, frente a lo que postulan De Miguel / F. Lagunilla (2000: 37-38), pueda decirse Ángel se salió tranquilamente de la fiesta, mientras que \#Ángel se salió tranquilamente de casa es anómalo. El tipo de adjunto locativo que acompaña al verbo nos da una clave de las características del evento en cada caso: si dicho adjunto designa un acontecimiento (o el lugar en el que se desarrolla uno), es muy probable que pueda inferirse de la aparición de se que ha habido algo en el transcurso de dicho acontecimiento que ha obligado al sujeto a abandonarlo (por ejemplo, que la fiesta era aburrida, o que había demasiada gente, o que se sintió mal), mientras que si designa un lugar, necesitamos más información para saber qué es lo que le ha impulsado a abandonarlo: Se salió de casa por el humo $o^{32}$. Un ejemplo muy ilustrativo de lo que queremos decir lo tenemos en el siguiente doblete:

(6) Salió de la carretera

(7) Se salió de la carretera

En la oración (6) el sujeto realiza la acción de manera "espontánea", sin que haya lugar a plantearse las motivaciones de su comportamiento, mientras que de (7) se infiere que hay una razón para que el sujeto actúe de ese modo, como puede ser, por ejemplo, un despiste, un momento de sueño, un patinazo o la acción de otro vehículo. De este modo creemos que se justifica la noción de media o media incoativa en este tipo de verbos: el evento se produce porque hay una motivación para ello, esa motivación afecta directamente al sujeto, que se ve implicado en el evento de un modo más o menos controlado. De este modo se explicaría también, creemos, que un verbo como reír carezca de rección, mientras que reírse rige siempre un argumento causativo:

(8) Me reí de Pedro

(9) *Reí de Pedro

Los matices semánticos de este tipo de construcciones son sutiles y susceptibles de diversa interpretación. Podría considerarse, por ejemplo, que con la incorporación del clítico, se delimita la causa o el origen, es decir, el comienzo del evento. Esta manera de abordar el problema es muy parecida a la de De Miguel y Fernández Lagunilla (2000) (ver $\S$ 3.2.).

32 En cualquier caso parece claro que el significado léxico del adverbial de modo no vale por sí sólo para explicar su incompatibilidad con ciertos usos de se. Esto significa que no son las propiedades semánticas de un adverbio como tranquilamente lo que permite su aparición junto a ciertos verbos con se, pues, como hemos visto, hay casos en los que su presencia es anómala. Inversamente, adverbios que no se refieren al estado del sujeto cuando culmina el evento sino al modo en que se lleva a cabo el evento, como rápidamente, sí pueden aparecer junto a verbos con clítico, frente a lo que afirman De Miguel / Fernández Lagunilla: Juan se salió rápidamente de la fiesta. 
Pero lo cierto es que no todos los ejemplos que pueden aducirse de verbos intransitivos con se presentan el mismo grado de seguridad a este respecto. En su estudio del verbo avéstico, Kellens (1984: 77) considera que la media dinámica destaca la determinación con la cual se lleva a cabo un movimiento. Esta definición del grupo es válida sólo en los casos en los que el motor que impulsa la realización del evento se localiza en el sujeto mismo, es decir, en casos como se fue pero no en se durmió. Así pues, resulta difícil definir con exactitud en qué consiste esta determinación, pues, como se ha dicho, en este tipo de verbos la medialidad adopta gran cantidad de matices semánticos expresivos, que en parte se relacionan con la aspectualidad pero que además tienen que ver con procesos fuertes de lexicalización. Así, si bien un verbo como salirse ofrece con relativa facilidad la lectura de causalidad que estamos postulando, en un verbo como irse esta causalidad queda difuminada en la idea incoativa más física de un "origen" a partir del cual se desarrolla la acción. En cualquier caso, el comportamiento de los verbos intransitivos con se dista mucho de presentar rasgos regulares, tal como señalan repetidamente los autores. Así, ni siquiera en su exhaustivo análisis, Sánchez López (2002) consigue aportar una explicación integradora, de modo que muchas cuestiones importantes relacionadas con el tema quedan tan sólo esbozadas.

2.4. El grupo 6. supone un grado de involuntariedad mayor, por cuanto que el sujeto es un ente inanimado. Por lo demás, es casi idéntico al tipo anterior cuando en este el sujeto es experimentante y no agente (por ejemplo, con verbos como caerse, dormirse, morirse, etc.); la diferencia es que en 5. el carácter medio-incoativo se produce sólo con verbos intransitivos, mientras que 6 . admite verbos transitivos e intransitivos, de modo que si la oración denota que hay un agente responsable, este no es ya interno sino que se localiza en el exterior del evento, lo cual es muy parecido a lo que sucede en el tipo siguiente ${ }^{33}$. Mendikoetxea (1999: 1643) distingue en este tipo de construcciones entre que el evento tenga como causa o motor una propiedad intrínseca del sujeto (En verano muchos bosques se queman) o que se produzca sin que esté claro cuál es la causa de su realización (La taza se ha roto). La primera es una construcción media-pasiva y designa un estado (tipo 7.), la segunda es media-incoativa y designa un proceso que da lugar a un cambio de estado (o posición). A este segundo tipo Sánchez López (2002: 87) lo llama "anticausativa", pues en ella se pierde el argumento de "causa" 34 . En estos dos tipos culmina la idea "medial" de que el sujeto es el origen y el final del evento, o en palabras de Benveniste, que es interior a él. El evento no se contempla ya como algo que alguien realiza, sino como algo que sucede espontáneamente. El paso siguiente, dentro de la ocultación del agente que da lugar a estructuras inacusativas, es la interpretación pasiva: el verbo designa ahora un evento deliberadamente provocado por un agente, aunque dicho agente no aparezca explícito.

33 De hecho, para Sánchez López (2002: 50), ambos tipos son modalidades de construcciones pasivas con se, donde se define explícitamente la construcción pasiva como aquella "cuyo sujeto gramatical corresponde con un objeto nocional". Nuestra interpretación de la pasividad es más restringida (ver abajo), pues es más semántica que sintáctica: pasiva es una construcción activa con el agente silenciado; en ella el verbo designa un evento que se lleva a cabo activa y voluntariamente, lo cual significa tanto como que el agente es animado, sólo que no se le cita, pues se adopta el punto de vista del resultado objetivo.

34 Lo cual no quiere decir que no se entienda que la hay. Al igual que en el grupo 5., la acción se presenta en sus consecuencias, silenciando sus posibles causas, entre otras cosas, porque puede que no sean fácilmente reconocibles. En ese sentido, el grupo 5. también sería "anticausativo". 
2.5. Los tipos 7. y 8. representan grupos aparte. Desde el punto de vista sintáctico, se muestran respectivamente bajo dos formas diferentes, la personal inanimada (Se quemó el bosque para acabar con la plaga) y la impersonal (No se sabe nada nuevo), en la que además ya no es relevante el rasgo de transitividad/intransitividad. Sin embargo, desde el punto de vista semántico, podrían ser considerados conjuntamente, pues el fenómeno que recogen ambos es el mismo: la pérdida definitiva del argumento interno. Repárese en que las oraciones (4) y (5) consignadas antes tienen exactamente la misma estructura semántica: ambas hacen referencia a un argumento externo y en ambas falta la alusión al argumento interno, pero sólo una de ellas, la (5), es sintácticamente impersonal, es decir, el único argumento presente no concuerda con el verbo. No obstante, es un hecho que las construcciones pasivas presentan muchas más restricciones que las impersonales en cuanto al tipo de sujetos que admiten. Como se ha señalado en muchas ocasiones, la interpretación pasiva es más fácil si el sujeto no es animado, y si lo es, entonces tienen una interpretación de tipo (Se necesita camarera). Sánchez López (2002: 57) lo explica describiendo la estructura argumental de estas pasivas, pues, afirma, no es habitual que un SN humano y determinado, siendo el sujeto gramatical, no pueda ser interpretado como el argumento externo del verbo. Esta restricción no se da en las impersonales, porque en ellas puede reconocerse un argumento externo, que aunque no se menciona, es inespecífico y se interpreta siempre como humano ${ }^{35}$.

En cualquier caso, lo que tenemos en ambos casos es un esquema actancial que se aparta de todos los anteriores, porque ya no hay correferencia entre el agente y el paciente o experimentante. A consecuencia de ello, se pierde todo contenido referencial, pues no se identifica con ninguno de los roles del enunciado. Se produce además una evolución respecto a los tipos anteriores en la medida en que se pasa de un proceso experimentado (voz media) a una acción padecida (voz pasiva), pero en una estructura en la que el agente ha recuperado, de nuevo, el control de la acción, como es propio de la diátesis activa. En un último momento, el representado por la construcción impersonal, se anula incluso el carácter intransitivador del clítico propio de su interpretación como marca de sujeto interno. De alguna forma, el ciclo se cierra pues se retoma de nuevo la transitividad y la agenticidad, aunque para ello haya habido que sacrificar la referencia específica al argumento interno y, por supuesto, el propio sujeto gramatical.

Como consecuencia de este proceso, se desarrolla ciertos valores secundarios, relacionados más o menos con la diátesis, que contribuyen en gran manera a crear inestabilidad o vacilación expresiva, es decir, valores que consideraríamos "poco estructurales". Merece la pena mencionar uno de los usos "desplazados" del clítico que más problemas de sistematización presenta. En él, el valor diatético se anula casi totalmente a favor de un valor que en otros casos es secundario, el aspectual, y, lo que es más importante, el clítico se convierte en un elemento expletivo, con todas las implicaciones estilísticas que ello implica.

\section{Se expletivo}

3.1. Acerca de este tipo de se es importante destacar, en primer lugar, los motivos de la elección de este término en lugar del más común "se aspectual". Ello explicará también por qué no incluimos los verbos intransitivos pronominales en este grupo, tal como hacen, 
por ejemplo De Miguel / Fernández Lagunilla (2000) o Sánchez López (2002). Esta última autora señala ya que el valor aspectual de culminación, que se postula para este tipo de construcciones (ver adelante), es una consecuencia propia de la aparición del clítico junto a los verbos que se da también en el se diatético. Puede pensarse, por tanto, que el valor aspectual es secundario y se relaciona con la mayor o menor intervención del agente en el evento ${ }^{36}$. En los ejemplos con verbos intransitivos (7) y (8) veíamos como, más que el aspecto télico del evento, lo relevante de la construcción era el hecho de que podía inferirse de ella una causa agentiva que explique el evento. Si esto es así, no puede decirse que el llamado "se aspectual" no altere las propiedades formales y semánticas del verbo intransitivo, como propone Sánchez López (2002: 122). Es innegable que en tales casos no se produce la intransitivación característica del se diatético, lo cual es lógico dado que partimos de verbos que sólo tienen un argumento, pero nuestra impresión es que, precisamente, la aparición del se en los verbos intransitivos provoca el efecto contrario: se produce una especie de transitivización de la estructura eventiva, pues se deja entrever la posibilidad de que haya un nuevo argumento controlando la realización del evento. En nuestra opinión, en esto consiste la especialización semántica que provoca el se sobre los verbos intransitivos.

3.2. El efecto del llamado "se aspectual" sobre los verbos transitivos no es igual a lo que acabamos de señalar para los intransitivos. La diferencia fundamental es que en las construcciones transitivas, este se es propiamente expletivo, pues ciertamente no modifica la estructura argumental del verbo, como sí lo hace el se diatético. Y en este caso es realmente el valor aspectual el que predomina sobre los matices diatéticos. De los dobletes que se producen aquí sí puede decirse que constituyen variantes expresivas del mismo verbo y, como tales variantes, cada una presenta sus propias restricciones de aparición. Nos referimos a los dobletes del tipo Ya he leído esa novela - Ya me he leído esa novela.

De lo anterior se desprende que aquí identificamos el se expletivo con el se aspectual cuando éste es claramente el valor predominante, por no decir el único, que puede adscribirse al clítico. Para concretar más exactamente este valor aspectual remitimos a la explicación de De Miguel / Fernández Lagunilla (2000). Según estas autoras, el se aspectual es un "operador aspectual que señala el punto culminante [de un evento] que da paso a un cambio de estado [en el objeto afectado]" ${ }^{\prime 37}$. Así, analizando la estructura interna de los eventos puede detectarse qué tipo de verbos admiten en principio este se: no se trata sólo de que designen telicidad, también tienen que indicar que previamente al final del evento ha tenido lugar un proceso y que tal proceso culmina en un punto al que le sigue un estado nuevo: son, por tanto, eventos complejos con varias fases que acaban cuando el objeto directo queda completado (a eso se refieren seguramente las autoras cuando hablan de "cambio de estado"). Ello explicaría por qué se puede decir Me he visto todas las peliculas de W. Allen pero no * Me he visto la costa ni *Ana se empujó el carrito (evento no delimitado) ni *Pedro se disparó el rifle (en sentido no reflexivo; objeto no completado).

Pero además de todo esto, hay que tener en cuenta que el carácter expletivo del clítico nos introduce en un terreno algo inestable en el que pueden participar activamente los as-

36 "Las transiciones o procesos télicos [...] están relacionados con sujetos agentes que controlan la acción" (Sánchez López, 2002: 121).

37 De Miguel / Fernández Lagunilla (2000: 31). 
pectos menos estandarizados de la lengua. Posiblemente sea en este grupo donde el estudio del clítico nos obligue a prestar más atención a la variación estilística, diastrática e incluso dialectal. Por lo general, se detectan tendencias más o menos sistematizables pero no se ha llegado a dar una explicación global de toda la casuística que puede atestiguarse. Por ejemplo, en la prensa hemos encontrado casualmente una cita de se expletivo en la que el uso del clítico no se compadece bien con la descripción que proponen De Miguel y Fernández Lagunilla. Pertenece al escritor Mario Vargas Llosa y puede entenderse como dialectalismo:

(10) El domingo pasado, en Barajas, en el aeropuerto de Madrid, mientras yo reclamaba unos pasajes pre-pagados en la ventanilla de Iberia, un ladrón se robó mi computadora. (El País, 10.11.02)

Este caso es anómalo según la teoría de De Miguel / F. Lagunilla porque robar es lo que las autoras llamarían un "logro simple", del mismo tipo de disparar.

A pesar de que en líneas generales la explicación de De Miguel / F. Lagunilla parece acertada, ejemplos como este ponen de manifiesto que no hay un análisis infalible de la estructura interna de los eventos capaz de prever todas las posibilidades de aparición del clítico en esta posición. De ahí viene también el carácter de forma "expresiva" o "enfática" que se le asigna tradicionalmente.

\section{Conclusiones}

Puede decirse que el clítico reflexivo es la forma de activar la diátesis media en español. Ahora bien, en español, como en todas las lenguas románicas, la diátesis no es una categoría formal sino sintáctico-semántica, lo cual multiplica las facetas bajo las que puede aparecer. Esto, unido al hecho de que la voz media se presenta conceptualmente en todas las lenguas bajo gran cantidad de matices expresivos de difícil sistematización, ha ayudado a desarrollar las posibilidades de empleo de se. Hemos intentado mostrar que el enfoque semántico es el único que garantiza una cierta homogeneidad en la descripción, homogeneidad que, de todas formas, es engañosa, pues no tiene en cuenta todas las variedades que escapan a la norma ${ }^{38}$. Si al denominador semántico común que aúna los usos de se lo llamamos "reflexividad", como hace Trujillo, tenemos que ser capaces de ampliar este concepto tanto a los procesos de pérdida de agentividad como a los verbos intransitivos o a los usos expletivos. Si lo entendemos como voz media, tenemos que analizar en detalle los elementos relevantes que intervienen en la categoría diatética, para explicar a partir de ellos los matices semánticos que presenta la medialidad en español. Estos matices se reflejarían en un continuo en el que el clítico va ganando primero, para perderlos después, los rasgos funcionales propios de un sujeto interno al predicado (intransitivización y medialidad), hasta lograr finalmente anular la posibilidad del sujeto gramatical en la construcción.

\footnotetext{
38 Hablar de "norma" o de "estándar" en este caso resulta más complicado que en otros, pues precisamente porque las gramáticas no han sido capaces de dar una explicación unitaria y convincente de este fenómeno es muy dificil determinar cuál es el uso "normal" y cuál es el desplazado. Asi, lo que para algunos hablantes es una forma de uso cotidiano y normal, puede causar extrañeza en los lingüistas, que, sin embargo, no disponen de argumentos gramaticales sólidos contra ella.
} 
En su valor "adverbial" como marca de aspecto es donde se localizan las mayores vacilaciones de uso. Estas vacilaciones afectan sobre todo a los verbos transitivos con se expletivo, pero también a los verbos intransitivos. Nuestra impresión es que aquí la descripción pierde parte de sus propiedades estructurales, como si el fenómeno difuminara sus contornos gramaticales en favor de unos valores expresivos de difícil sistematización. En efecto, si primariamente el se es un clítico intransitivador y diatético, los usos en los que no aporte ninguno de estos valores son alejamientos gramaticales del prototipo que, como tales, darán previsiblemente problemas de descripción a la gramática. En este sentido falta, a nuestro entender, un estudio variacional más completo de estos usos especiales y (seguramente como consecuencia de ello) una explicación coherente que permita la transición del valor reflexivo-diatético del clítico a su valor aspectual ${ }^{39}$.

Da la impresión de que en las lenguas hay ciertos fenómenos que, por mucho que se esfuercen los lingüistas, se resisten a presentar un comportamiento homogéneo, fácilmente describible en términos estructurales, de modo que casi podríamos decir que son fenómenos "antiestructurales". En nuestra opinión, el se es claramente uno de esos fenómenos. Cada acercamiento a él consigue a lo sumo aportar un nuevo elemento de reflexión, pero parece que las piezas no terminan de encajar nunca. Sin duda, es esto lo que lo convierte en un tema apasionante, fuente de innumerables e interesantes reflexiones lingüísticas.

\section{Referencias bibliográficas}

Alcina Franch, J. y J. M. Blecua (1975): Gramática española. Barcelona, Ariel.

Bassols de Climent, M. (1983): Sintaxis latina. Madrid, C.S.I.C.

Benveniste, E. (1966): "Actif et moyen dans le verbe". En Benveniste, E.: Problèmes de linguistique général. Paris, Gallimard, págs. 168-175.

Bogard, S. (1999): "Duplicación y clausura argumental: Dos funciones del clítico reflexivo en español”, Español actual, 71, págs. 41-48.

Cartagena, N. (1972): Sentido y estructura de las construcciones pronominales en español. Concepción-Chile, Publicaciones del Instituto central de lenguas - Universidad de Concepción.

Coseriu, E. (1981): "El principio de la funcionalidad". En Coseriu, E.: Lecciones de lingüistica general. Madrid, Gredos.

De Miguel Aparicio, E. y M. Fernández Lagunilla (2000): "El operador aspectual se", REL, 30,1, págs. 13-43.

Gotō, T. (1987): Die "I. Präsensklasse" im Vedischen. Viena, Österreichischen Akademie der Wissenschaften.

Humbert, J. (1945): Syntaxe grecque. Paris, Klincksieck.

Hummel, M. (2000): Adverbale und adverbalisierte Adjektive im Spanischen. Tübingen, Gunter Narr.

Iglesias Bango, M. (1991): La voz en la gramática española. León, Centro de estudios metodológicos e interdisciplinares - Universidad de León.

Kellens, J. (1984): Le verbe avestique. Wiesbaden, Dr. Ludwig Reichert.

Luján, M. (1976): "The Analysis of Reflexive Inchoatives". En Hensey, F. (ed.): Current Studies in Romance Linguistics. Washington DC, Georgetown University Press, págs. 377-387. 
Manney, L. J. (1998): Middle voice in Modern Greek: meaning and function of an inflectional category. Amsterdam / Philadelphia, John Benjamins Publishing Co.

Martin Zorraquino, M. A. (1979): Las construcciones pronominales en español. Paradigma y desviaciones. Madrid, Gredos.

Melis, L. (1996): "Las construcciones pronominales del verbo en francés y en español: una comparación entre sistemas lingüísticos cercanos". En De Kock, J. (dir.): Gramática española. Enseñanza e investigación. Apuntes metodológicos. Salamanca, Universidad de Salamanca. Vol. I,4: Lingüística contrastiva, págs. 159-206.

Mendikoetxea, A. (1999): "Construcciones con se: medias, pasivas e impersonales". En Bosque, I. y V. Demonte (dirs.): Gramática descriptiva de la lengua española. Madrid, Espasa. Vol. 2, cap. 26, págs. 1631-1722.

Molina Redondo, J. A. (1974): Usos de se. Cuestiones sintácticas y léxicas. Madrid, SGEL.

Monge, F. (1955): "Las frases pronominales de sentido impersonal en español", $A F A$, VII, págs. 7 102.

Sánchez López, C. (2002): “Las construcciones con se. Estado de la cuestión”. En Sánchez López, C.: Las construcciones con se. Madrid, Visor Libros, págs. 13-163.

Trujillo, R. (1992): "La reflexividad". En Scripta Philologica in Honorem Juan M. Lope Blanch. México, UNAM. I, págs. 143-168.

Vera Luján, A. (1996-97): "Esquemas oracionales ergativos reflexivos", ELUA, 11, págs. 385-409.

Zagona, K. (1996): "Composionality of Aspect: Evidence from Spanish Aspectual Se". En Parodi, C. (ed.): Aspects of Romance Linguistics. Washington DC, Georgetown University Press, págs. 475-488. 